\title{
Correlation between Liver Ultrasonography with AST and ALT Value in Suspect Hepatitis
}

\author{
Ana Majdawati ${ }^{1 *}$ (D) , Adang Muhammad Gugun² ${ }^{2}$ \\ ${ }^{1}$ Department of Radiology, Medical Study Program, Faculty of Medicine Health Sciences, Universitas Muhammadiyah \\ Yogyakarta, Bantul, Indonesia; ${ }^{2}$ Department of Patologi Klinik, Medical Study Program, Faculty of Medicine Health Sciences, \\ Universitas Muhammadiyah Yogyakarta, Bantul, Indonesia
}

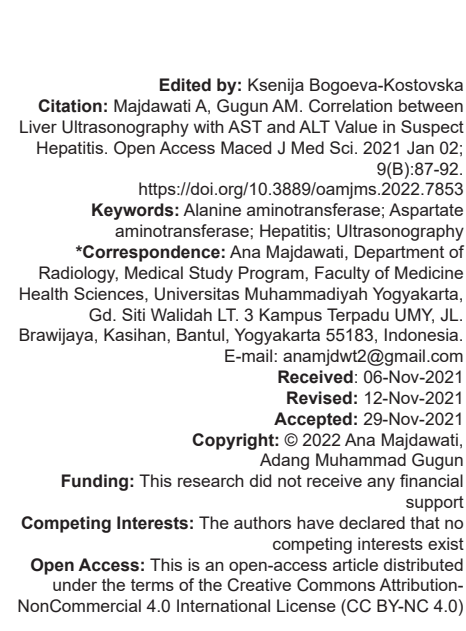

\section{Introduction}

Hepatitis is inflammation that occurs in the liver, which is a systemic infection by viruses or toxic including alcohol, associated with a broad spectrum of clinical manifestations from asymptomatic infection, jaundice to liver necrosis that produces a characteristic collection of clinical, biochemical, and cellular changes [1], [2]. Hepatitis is a worldwide health problem, including in Indonesia. The leading cause of Hepatitis is a virus consisting of Hepatitis A, B, C, D, E viruses. Hepatitis $A$ and $E$ often appear as extraordinary events and are transmitted fecal-oral and are associated with clean and healthy living habits, which are acute and can heal well. Hepatitis $B, C$, and D are rare and transmitted parenterally. They are chronic, causing Cirrhosis and Liver Cancer. The global prevalence of Hepatitis shows that two billion people have been infected, with $75 \%$ of them living in Southeast Asia. As many as 240 million people are chronic carriers with a risk of cirrhosis and liver cancer. The mortality rate related to Hepatitis reaches 500 thousand to 700 thousand per year.
Indonesian data shows that $\mathrm{HBsAg}(+)$ is around three to $22 \%$. This figure makes Indonesia a high endemic area. Basic health research data in 2013 showed that the prevalence of Hepatitis B was $7.1 \%$. Around 18 million people were infected with Hepatitis $B$, and nine million develop chronic disease (50\%). According to the WHO classification, Indonesia is classified as an area with moderate and high Hepatitis prevalence [3].

Hepatitis is sometimes accompanied by increased levels of Aspartate Aminotransferase (AST) or Serum Glutamic Oxaloacetic Transaminase (SGOT) and Alanine Aminotransferase (ALT) or Serum Glutamic Pyruvic Trans-aminase (SGPT). AST/SGOT and ALT/ SGPT are often considered hepatic enzymes due to their high concentration in hepatocytes, but the only ALT is specific. In liver disease, serum AST and ALT levels generally rise and fall together. When the hepatocytes are injured, these enzymes that are normally intracellular enter the bloodstream. Reference values for SGPT/ALT and SGOT/AST are male: 0-50 U/L female: 0-35 U/L [4]. Increased AST and mild ALT with a ratio of AST: ALT $<1$, occurs in chronic Hepatitis (Hepatitis B and C), Celiac disease, alpha-1-antitrypsin deficiency, and fatty 
liver non-alcoholic disease, drugs, hyperthyroidism, autoimmune liver, and metabolic syndrome. Increased AST and mild ALT with AST include ALT> 1 in cirrhosis, Rhabdomyolysis, Budd-Chiari Syndrome, and Wilson disease. Moderate-severe increases with AST and ALT 5-15 x normal or > $15 \times$ normal, in acute viral Hepatitis, ischemia, and hepatotoxic drugs [5], [6], [7].

Ultrasonography (USG), liver cell damage, and this inflammatory process sometimes have not seen changes in the parenchymal echostructure, but sometimes changes can be seen when the process is advanced or causes significant damage. Laboratory tests of suspected Hepatitis that are often performed include physiological liver tests, namely AST and ALT. Doctors often request hepatic USG for Hepatitis cases in hospitals and health services. Almost every patient with suspected Hepatitis is ordered to do USG of the abdomen or USG of the liver. Based on the prevalence according to the $\mathrm{WHO}$ and the frequent cases of Hepatitis subjected to USG of the liver, the applicant would like to see an USG image of the liver-related to the AST and ALT values in patients with suspected Hepatitis. Research is needed to review eligibility for referral based on AST and ALT results. Several studies have been carried out related to the correlation of liver USG in cases of acute and Chronic Hepatitis, including assessing the liver's size and structure, the surface of the liver, the thickness of the portal vein, the size of the spleen, and the thickening of the gallbladder wall [8], [9]. In this study, what is different from other studies about the USG of the liver, which includes size, hepatic parenchymal echostructure, portal vein diameter, and thickening of the gallbladder in patients with suspected Hepatitis with AST (SGOT) or ALT (SGPT) enzyme values?

\section{Methods}

This research method is cross-sectional with a $2 \times 2$ table, which revealed the correlation between liver USG images with AST and ALT values in patients with suspected Hepatitis [10]. The samples size was 100 patients with suspected Hepatitis 18-65 from the polyclinic, inpatient at Panti Rapih, Yogyakarta, Hospital. The largest sample was in adolescents and adults 17-38 years old, namely $56 \%$. The samples were examined for AST and ALT blood levels and continued with liver USG, which assessed the size, echostructure, and edges of the liver, the portal vein's diameter, thickening of the gallbladder, and the size of the spleen (Figure 1).

This study was conducted from August to June $2016 / 2017$, taken consecutively with the conditions that met the inclusion and exclusion criteria. Inclusion criteria included patients with suspected Hepatitis 18-60 who performed liver enzyme function tests, namely AST and ALT levels, and patients who underwent USG of the liver. Meanwhile, exclusion criteria included USG results obtained mass/nodule and patients with incomplete examination results. The variables of this study consisted of (independent variables) are the results of hepatic USG, which included: size, hepatic echo structure, edge/surface of the liver, the diameter of the portal vein, and thickness of the wall of the gallbladder with normal and abnormal categories. The dependent variable was AST and ALT levels in patients with suspected Hepatitis (normal and abnormal categories)

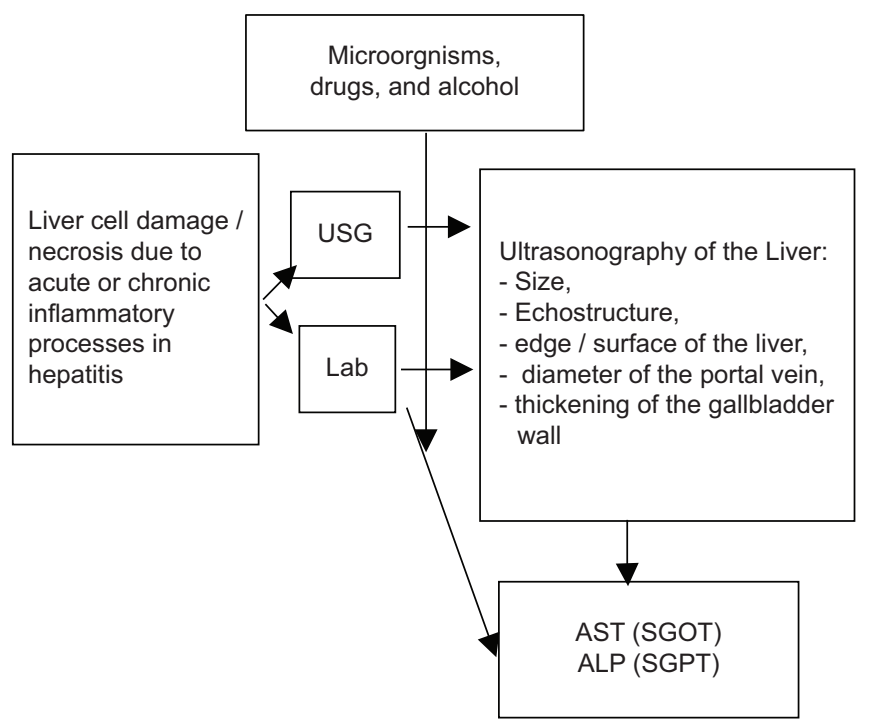

Figure1: Conceptual framework of the research

\section{Sample size of the research}

Sample Formula

$N=\frac{Z^{2} \times P}{S D^{2}}$

Based on the assumption of sensitivity $(P)$ : 95\%, standard deviation: 5\%, 95\% confidence interval ( $Z=1.96)$, the sample size was 73 . In the probability of dropping out, the sample size was at least 80 . The correlation between the liver USG images, including echostructures, liver size, the wall thickness of gallbladder, the diameter of portal veins with AST, and ALT values was a chi-square hypothesis getting p-value [11].

The operational definitions of this research variable were as follows: USG examination of the liver (independent variables) was an examination using a transducer whose frequency was between 3.5 and $5 \mathrm{M} . \mathrm{Hz}$, where the transducer was placed subcostal from the epigastrium to the flank area. Liver USG examination, including:

1. Hepatic echostructure was an echogenic picture of the liver on USG compared to the right kidney and was classified into 3 criteria:

- Normal: The hepatic echostructure is 
slightly higher than the kidney

- Hyperechoic/abnormal: When the echogenicity of the liver is higher than that of the kidney or the same

$\bullet$

Hypoechoic/abnormal: When the echogenicity of the liver is lower than that of the kidneys.

2. The liver's size, that is, sagittal/longitudinal slices, was drawn a line from the mid of the clavicle to the lower edge of the liver.

- $\quad$ Normal, if size of longitudinal slices less than $15.5 \mathrm{~cm}$

- Hepatomegaly/abnormal, if size of longitudinal slices higher than $15.5 \mathrm{~cm}$.

3. Liver surface

- Normal, if the surface of the liver is smooth

- Irregular/Abnormal, if the surface of the liver is irregular, lumpy.

4. Gall bladder wall:

- Normal, if wall thickening less than $3 \mathrm{~mm}$

- $\quad$ Thick wall/abnormal, if wall thickening 4-15 $\mathrm{mm}$ or double layer wall.

5. Portal vein wall:

- Normal, if the portal vein wall is less than $5 \mathrm{~mm}$.

- $\quad$ Thickening/abnormal, if the portal vein wall with hyperechoic features and higher than $5 \mathrm{~mm}$.

Liver function test (LFT) (dependent variable) consists of AST/SGOT and ALT/SGPT values:

1. SGOT: Serum glutamic oxaloacetic transaminase or other names AST, a hepatic function marker enzyme obtained from laboratory results, if there is an increase, in

Table 1: Data characteristics of the subjects

\begin{tabular}{|c|c|c|}
\hline Information & Total & Percentage \\
\hline \multicolumn{3}{|l|}{ Age } \\
\hline $17-27$ & 29 & $29 \%$ \\
\hline $28-38$ & 27 & $27 \%$ \\
\hline $39-49$ & 20 & $20 \%$ \\
\hline $50-59$ & 14 & $14 \%$ \\
\hline $60-78$ & 10 & $10 \%$ \\
\hline \multicolumn{3}{|l|}{ Gender } \\
\hline Male & 68 & $68 \%$ \\
\hline Female & 32 & $32 \%$ \\
\hline \multicolumn{3}{|l|}{ Complaint } \\
\hline Fever, nausea, epigastric pain & 87 & $87 \%$ \\
\hline Yellow eyes/skin/urine & 9 & $9 \%$ \\
\hline Abdominal pain & 2 & $2 \%$ \\
\hline Others (edema, tightness, etc.) & 2 & $2 \%$ \\
\hline \multicolumn{3}{|l|}{ Etiology/types of Hepatitis } \\
\hline Viral Hepatitis A & 46 & $46 \%$ \\
\hline Viral Hepatitis B & 26 & $26 \%$ \\
\hline Viral Hepatitis C & 19 & $19 \%$ \\
\hline Hepatitis reactive/undefined & 5 & $5 \%$ \\
\hline $\begin{array}{l}\text { Hepatitis Non-viral causes (toxoplasma and Salmonella } \\
\text { thypi) }\end{array}$ & 4 & $4 \%$ \\
\hline KHS & 1 & $1 \%$ \\
\hline \multicolumn{3}{|l|}{ Laboratory (liver function) } \\
\hline \multicolumn{3}{|l|}{ AST (SGOT) } \\
\hline Normal & 10 & $10 \%$ \\
\hline & 90 & $90 \%$ \\
\hline \multicolumn{3}{|l|}{ ALT ((SGPT) } \\
\hline Normal & 12 & $12 \%$ \\
\hline Abnormal & 88 & $88 \%$ \\
\hline
\end{tabular}

Table 2: Results of liver USG on hepatitis suspect

\begin{tabular}{lll}
\hline Information & Total & Percentage \\
\hline $\begin{array}{l}\text { The size of the liver } \\
\text { Normal }\end{array}$ & 70 & $70 \%$ \\
$\quad$ Abnormal & 30 & $30 \%$ \\
Echostructure & & \\
$\quad$ Normal & 87 & $87 \%$ \\
$\quad$ Abnormal & 13 & $13 \%$ \\
Liver surface & & $93 \%$ \\
$\quad$ Normal & 93 & $7 \%$ \\
$\quad$ Abnormal & 7 & $96 \%$ \\
Wall portal vein & & $4 \%$ \\
$\quad$ Normal & 96 & $78 \%$ \\
$\quad$ Abnormal & 4 & $22 \%$ \\
$\quad$ Gall bladder & & \\
$\quad$ Abnormal & 78 & \\
\hline
\end{tabular}

general, it indicates a disturbance in hepatic function

2. SGPT: Serum glutamic pyruvic transaminase or another name ALT, an enzyme marker of the hepatic function obtained from laboratory results; if there is an increase, it generally indicates a disturbance in hepatic function. Reference values for SGPT/ALT and SGOT/ AST include Male: 0-50 U/L Female: 0-35 U/L. Abnormal ALT and AST if the value is more or less than the normal value in both men and women [4], [12].

\section{Results}

Table 1 shows the number of study subjects with 100 people aged 17-78 years old. The largest number of samples was adolescents and adults 17-38 years old, more than 50\% (56\%). It became the major Hepatitis patients in this study as Hepatitis A Virus $46 \%$ is followed by Hepatitis B Virus $26 \%$, Hepatitis C Virus 19\%, and the rest Hepatitis was due to other reasons $9 \%$. The most symptoms experienced by patients were nausea, vomiting, fever, and epigastric pain of $87 \%$, yellow color of the skin and eyes $9 \%$, and other complaints of $4 \%$. The number of subjects is 100 samples of suspected Hepatitis, AST levels were normal $10(10 \%)$ and abnormal 90 (90\%), ALT levels were normal $12(12 \%)$, and abnormal 88 (88\%).

Table 2 shows the results of an USG of the liver, including size, echostructure of the liver, the thickness of the gallbladder walls, and the thickness of portal vein walls.

Table 3 shows statistically the image of liver USG, which included size, echostructure, and diameter of the portal vein, which had a significant relationship with the increase in AST and ALT values. The liver echostructure was statistically significant (chi-square) on the AST and ALT values with p: 0.05 and 0.03 and the lambda contingency coefficient correlation with $r$ value was 0.19 , indicating that the closeness of the hepatic echostructure relationship with AST and ALT values was very weak. 
Table 3: Table of relationship between liver USG with AST and ALT value

\begin{tabular}{|c|c|c|c|c|}
\hline \multirow[t]{2}{*}{ Independent variable } & \multicolumn{2}{|l|}{$\mathrm{p}$} & & $\begin{array}{l}\text { OR } \\
\text { AlT/SGPT }\end{array}$ \\
\hline & AST/SGOT & ALT/SGPT & AST/SGOT & ALT/SGPT \\
\hline Echostructure & $0.051^{*}$ & $0.023^{\star}$ & $6.283^{*}$ & $1.981^{*}$ \\
\hline Size & $0.029^{*}$ & 0.081 & $5.407^{*}$ & 0.232 \\
\hline Liver surface & 0.360 & 0.847 & 0.00 & 0.805 \\
\hline Thickened off wall portal vein & $0.006^{*}$ & $0.017^{*}$ & 0.091 & 0.116 \\
\hline Thickened of gallbladder & 0.077 & $0.050^{*}$ & 0.000 & 0.000 \\
\hline
\end{tabular}

\section{Discussion}

Based on the WHO data, in July 2012, the highest incidence of Hepatitis was caused by the Hepatitis A virus, which mostly attacked children and adults, followed by viral Hepatitis B, C, D, and E. The highest incidence of Hepatitis was mostly those between the ages of 25 and 54 years old. It is based on the results of this study that most Hepatitis patients were about the age of $28-49$ years old $(47 \%)$, and the most common type was viral Hepatitis A ( $46 \%$ of all samples) [3], [13]. Acute viral hepatitis is caused by Viral Hepatitis A, and E. Chronic Hepatitis included Viral Hepatitis B and C, D, and alcoholics that cause Cirrhosis, liver fibrosis, and Hepatocellular carcinoma [13], [14]. Geographically and in poor public health conditions, this disease occurs in many developing countries, including Indonesia. Indonesia is the country with the secondhighest number of Hepatitis cases in Southeast Asia after Myanmar. The most common clinical symptoms of Hepatitis are nausea, vomiting, epigastric pain, and fever, especially for acute Hepatitis, according to this study [3], [15]. This is by following the case in the world, including Indonesia. Hepatitis is mostly caused by infection with Hepatitis A virus and occurs at productive age [13].

The liver function showed that, out of 100 samples, those with clinical Hepatitis with normal AST (SGOT) values were $10 \%$ and abnormal $90 \%$, while ALT (SGPT) values were normal $12 \%$ and abnormal $88 \%$. In our study, the results of liver USG consisting of echo structure, size, liver surface, wall portal vein, and gall bladder thickening showed abnormal results were lower (4-30\%) than normal (70-96\%).

In this study, it was seen that the AST and ALT values showed more abnormal numbers than normal, while the results of the USG examination showed normal USG images, the numbers were greater than normal. This happens because the AST and ALT enzymes will affect the image of abnormalities USG of the liver which includes echostructure, size, liver surface, portal vein wall thickening, and gall bladder thickening, if the increase is large enough, which is more than 1.5-5 times the normal value. The increase in AST and ALT histologically affects the damage to liver hepatocytes, although USG has not shown any macroscopic anatomical changes. Several factors influence changes in the anatomical echostructure of USG imaging, namely the level of AST and ALT of liver hepatocytes, exposure time to microorganisms and substances that cause injury to the liver and surrounding organs, the patient's immune system, and other accompanying diseases [16], [5].

This study's sample's USG results showed a significant relationship with the AST and ALT values, including the hepatic echostructure and portal vein wall thickness. Liver size showed a significant relationship with AST values and gallbladder wall thickening with ALT values.

Acute and chronic hepatitis is determined by the increase, heterogeneity of the echostructure, and swelling of the liver. USG alone is not enough. Usually, it is prescribed after assessing the degree of liver damage. The sign of acute hepatitis is the diffuse decrease in hepatic echogenicity. Most often, the cause of hepatomegaly (organ enlargement) in this disease, for which a characteristic uniform decrease in echogenicity of liver tissue. Due to these changes, the walls of the portal vein branches look brighter - a symptom of the "starry sky." Quite often, thickening of the walls of the gallbladder can be detected. The specialist may also notice alarming signals of inflammation, fibrosis, and changes in organ tissue density, which is characteristic of chronic hepatitis [7], [9].

Serum ALT (which was earlier known as SGPT) and serum AST (which was earlier known as SGOT) are released from the hepatocytes into the circulation after hepatocyte injury or death. Infection with the hepatitis viruses results in sudden and massive necrosis of the hepatocytes, which leads to the release of ALT and AST enzymes from the cell cytoplasm into the blood circulation. LFTs have two components: bilirubin and various liver enzymes. For a complete and accurate interpretation of LFT in a person, we need to look at these carefully. If liver enzymes are predominantly elevated rather than bilirubin, then we need to look at which group of enzymes are elevated: those located within the hepatocytes such as ALT and AST; or those located inside the cholangiocytes such as alkaline phosphatase and GGT [14], [17].

In a normal person as well as most patients with liver disease, ALT is higher than AST. There are two reasons for the higher ALT levels: first, ALT is present in the cytoplasm and is released by minor injuries; second, ALT has a longer half-life than AST and life than AST and hence remains in the blood for a longer time. It is common practice to look at the ALT/ AST ratio though it has a limited role in the diagnosis and management of liver diseases. Normal ALT levels are higher than AST levels. In certain conditions, AST could elevate more than ALT like (1) alcoholic liver disease results in mitochondrial toxicity and pyridoxal phosphate, which is a co-factor for AST; (2) Wilson disease results in subclinical hemolysis and release of AST; (3) the presence of liver cirrhosis; once liver cirrhosis is established, AST remains higher than ALT 
because of destroyed sinusoidal architecture, which results in impaired clearance of AST [7], [16], [17].

The liver's size had a significant relationship with the AST value, mean the $p=0.029$ and OR 5.407, indicating that the liver's size (hepatomegaly) had a 5 times tendency for high or abnormal AST values. AST showed an acute infectious process so that the size of the liver usually appeared large, and the USG image showed a blunt left lobe. According to the theory, the increase influences liver cell damage in enzymes produced by liver cells, which are called AST and ALT, with moderate-severe increases with AST and ALT 5-15 times with normal or >15 times normal. In acute viral Hepatitis, ischemia, and Hepatotoxic drugs, the actual theory that specifically indicates liver cell damage is the ALT enzyme, where the increase in the enzyme indicates an acute liver inflammation, ALT: AST ratio $<1$. ALT is mainly aggregated in the cytosol in liver hepatocytes. ALT activity is about 3000 times higher than serum AST activity. When a liver injury occurs, new ALT is released from the injured liver cells and causes a significant increase in serum ALT activity. ALT can also be found in muscle, adipose tissue, intestine, colon, prostate, and brain. However, the concentration of ALT in organs other than the liver is much lower than in the liver. AST: ALT ratio > 1 indicates Chronic Hepatitis [17], [18].

Viral hepatitis infection is the leading or secondary cause of ALT elevation in populations worldwide. ALT activity is an indicator of liver injury in patients with acute and chronic viral hepatitis. ALT values with low levels affect the size of the liver. Liver size is also affected by reduced blood flow to the liver [8]. AST enzyme causes necrosis process in the hepatic cells (hepatocytes), indicating a chronic inflammatory process. AST is specific for muscle tissue (heart and skeletal), kidneys, brain, pancreas, and red blood cells, and some of the liver. Elevated AST and ALT levels do not indicate the severity and extent of liver parenchymal damage; an increase in serum levels indicates leakage of damaged cells [9], [15], [19].

The AST and ALT values determine the gallbladder wall thickness or contracted bile wall. In this study, the relationship between gallbladder wall thickening significantly increased ALT values ( $p: 0.050)$. Some of the causes of the thickening of the gallbladder wall were acute cholecystitis, cirrhosis, dengue fever, falciparum malaria, heart failure, severe malnutrition, ascites, and sepsis. Gallbladder wall thickening is not specific for acute viral Hepatitis but is very common in acute Hepatitis. The gallbladder wall's mean thickness was $6 \mathrm{~mm}$, with a maximum recorded thickness of $11 \mathrm{~mm}$ in developing countries [9]

Portal vein wall thickening had a significant relationship with the AST and ALT values of clinical Hepatitis patients, p: 0.06 and 0.02 , respectively. It occurred as, in chronic Hepatitis, there was contracted liver tissue or fibrosis and resulted in blocking the portal vein. Enlarged portal hepatic lymph nodes were commonly found on USG of acute Hepatitis cases. This thickening is usually less than $1 \mathrm{~cm}$ in size and oval in shape with isoechoic or hypoechoic echostructure in the portal vein's central lumen, which contains fat. The porta hepatic node's appearance is reactive enlargement secondary to inflammation in the liver and associated with significant hepatocellular degeneration of the vacuole with increased brightness and visualization of the portal vein [9], [15].

The findings of this study indicated that there was a significant relationship between the increase in hepatic echostructure with AST (p: 0.051; OR: 6.283) and ALT (p: 0.023; OR: 1.981) values. This result indicated that the increase in hepatic echostructure tended to increase the AST value 6-fold. The ALT value increased 2-fold compared to the liver USG results without increasing the echostructure. The clinical course of a person giving clinical manifestations in acute Hepatitis infection was 7 days, and several studies within 7 days had caused changes in the reaction of enzymes in the liver, including AST and ALT, which had increased from low to high, indicating the course of liver infection or Hepatitis from acute to chronic. The use of AST and ALT values caused changes in the hepatic structure from fibrosis, nodular to cirrhosis, which caused changes in the structure, size, left lobe edge, liver surface, changes in the thickness of the gallbladder wall, and thickening and diameter of the lumen or portal vein wall [9], [14], [15].

The results of this study indicated a relationship between changes in morphology or liver anatomy on USG examination with the course of infection, as indicated by an increase in AST and ALT values. USG is an inexpensive, easy, non-invasive examination, and the results are quickly identified to the initial evaluation of diagnosis and follow-up therapy, whether the Hepatitis disease is getting worse or getting better [9], [15]. Changes in the hepatic echostructure and blunt edge of the liver's left lobe on hepatic USG showed a significant association with the course of acute and chronic Hepatitis [15], [20].

\section{Conclusions}

The results of this study indicated a significant relationship between the hepatic USG image, namely, hepatic parenchymal echostructure and portal vein wall thickness with AST (SGOT) and ALT (SGPT) hepatic function values; liver size with AST (SGOT) values, and gallbladder wall thickening with ALT (SGPT) values.

This study, which showed a significant correlation between ultrasound images of the liver with ALT and AST values, was liver echostructure and portal vein wall thickening. Liver size should have a significant correlation with ALT values compared to AST, while gallbladder wall thickening is associated with bilirubin 
values associated with post-hepatic hepatitis, due to obstruction in the bile ducts of the gallbladder. The research subjects were the most cases of hepatitis $A$, followed by Hepatitis $B$ and $C$. While the other causes were not explained in detail so that it affected the results of the study. In the future, prospective studies need to be carried out by distinguishing types of nonviral hepatitis (cause alcoholic, the drug induces).

Based on the results of the study, USG is an essential radiological modality to be used as a diagnostic support tool and as a tool to follow-up cases of Hepatitis, both acute and chronic Hepatitis.

\section{Acknowledgments}

We would like to thank all medical staff in the medical record section, radiology Installation, and Radiology department at Panti Rapih Hospital Yogyakarta Indonesia for having provided the data needed for this research until the manuscript has been finished. Hopefully, this article is useful as a reference that can be used as a learning material and is essential for evaluating medical services in Hepatitis cases.

\section{References}

1. 1. Franco E, Meleleo C, Serino L, Sorbara D, Zaratti L, Hepatitis A: Epidemiology and prevention in developing countries. World J Hepatol. 2012;4(3):68-73.

2. Roter DL, Hall JA, Aoki Y. Physician gender effects in medical communication: A meta-analytic review. J Am Med Assoc. 2002;288(6):756-64.

3. Balitbangkes. Situasi dan Analisis Hepatitis di Indonesia. Pusdatin Kemenkes RI. 2014. p. 1-8.

4. Newsome PN, Cramb R, Davison SM, Dillon JF, Foulerton M, Godfrey EM, et al. Guidelines on the management of abnormal liver blood tests. Gut. 2018;67(1):6-19. https://doi.org/10.1136/ gutjnl-2017-314924

PMid:29122851

5. Vagvala $\mathrm{SH}, \mathrm{O}$ 'Connor SD. Imaging of abnormal liver function tests. Clin Liver Dis (Hoboken). 2018;11(5):128-34. https://doi. org/10.1002/cld.704

PMid:30992803

6. Botros M, Sikaris KA. The de ritis ratio: The test of time. Clin Biochem Rev. 2013;34(3):117-30.

PMid:24353357
7. LurieY, Webb M, Cytter-Kuint R, Shteingart S, Lederkremer GZ. Non-invasive diagnosis of liver fibrosis and cirrhosis. World $\mathrm{J}$ Gastroenterol. 2015;21(41):11567-83. https://doi.org/10.3748/ wjg.v21.i41.11567 PMid:26556987

8. Afzal S, Masroor I, Beg M. Evaluation of chronic liver disease: Does ultrasound scoring criteria help? Int J Chronic Dis. 2013;2013:326231. https://doi.org/10.1155/2013/326231 PMid:26464843

9. Maurya V, Ravikumar R, Gopinath M, Ram B. Ultrasound in acute viral hepatitis: Does it have any role? Med J D Y Patil Vidyapeeth. 2019;335-9.

10. Dahlan S. Langkah-Langkah Membuat Porposal Penelitian Bidang Kedokteran dan Kesehatan. $2^{\text {nd }}$ ed. Jakarta: Sagung Seto; 2012

11. Dahlan M. Langkah-langkah membuat proposal penelitian bidang kedokteran dan kesehatan: Menentukan besar sampel. In: Dahlan M, editor. Seri Evidence Medicine. $2^{\text {nd }}$ ed. Indonesia: Sagung Seto; 2016. p. 79-98.

12. Bates JA. Abdominal Ultrasonography. How, Why and When $2^{\text {nd }}$ ed. Amsterdam, Netherlands: Elsevier; 2005.

13. WHO. Executive Summary-Global Hepatitis Report, 2017. Geneva: World Health Organization; 2017.

14. Wu S, Tu R, Liang X. Patchy echogenicity of the liver in patients with chronic hepatitis $B$ does not indicate poorer elasticity. Ultrasonography. 2019;38(4):327-35. https://doi.org/10.14366/ usg. 18071

PMid:31302950

15. Maàji SM, Yakubu A, Odunko DD. Pattern of abnorma ultrasonographic findings in patients with clinical suspicion of chronic liver disease in Sokoto and its environs. Asian Pac J Trop Dis. 2013;3(3):202-6. https://doi.org/10.1016/ S2222-1808(13)60041-9

16. Liu Z, Que S, Xu J, Peng T. Alanine aminotransferaseold biomarker and a new concept: A review. Int J Med Sci. 2014;11(9):925-35. https://doi.org/10.7150/ijms.8951 PMid:25013373

17. World Health Organization. Training Workshop on Screening Diagnosis, and Treatment of Hepatitis B and C-Session 11: Clinical Management of Hepatitis B Virus Infection: Case Studies. Geneva: World Health Organization; 2020. p. 1-45.

18. Malakouti M, Kataria A, Ali SK, Schenker S. Elevated liver enzymes in asymptomatic patients-what should I do? J Clin TransI Hepatol. 2017;5(4):394-403. https://doi.org/10.14218/ jcth.2017.00027

PMid:2922610

19. Summers JA, Radhakrishnan M, Morris E, Chalkidou A, Rua T, Patel $A$, et al. Virtual Touch ${ }^{\mathrm{TM}}$ quantification to diagnose and monitor liver fibrosis in hepatitis B and hepatitis C: A NICE medical technology guidance. Appl Health Econ Health Policy. 2017;15(2):139-54. https://doi.org/10.1007/s40258-016-0277-7 PMid:27601240

20. Cho YS, Jeong WK, Kim Y. Ultrasonographic morphological diagnosis of chronic liver disease: 2-dimensional shear wave elastography as an add-on test. Ultrasonography. 2020;39(3):272-80. https://doi.org/10.14366/usg.20009 PMid:32299199 